ISSN 1422-8599

www.mdpi.com/journal/molbank

Short Note

\title{
Methyl 4-[(Benzoylamino)methoxy]benzoate
}

\section{Emil Popovski $^{1{ }_{*},}$, Kristina Mladenovska ${ }^{2}$ and Ana Poceva Panovska ${ }^{2}$}

1 Institute of Chemistry, Faculty of Natural Sciences \& Mathematics, Ss. Cyril and Methodius University, Arhimedova 5, PO Box 162, 1000 Skopje, Macedonia

2 Department of Drug Design and Metabolism, Faculty of Pharmacy, Ss. Cyril and Methodious University, Vodnjanska 17, 1000 Skopje, Macedonia

* Author to whom correspondence should be addressed; E-Mail: popovski.emil@gmail.com.

Received: 1 December 2010 / Accepted: 21 December 2010 / Published: 24 December 2010

\begin{abstract}
Methylparabene (2) was simply benzamidomethylated with (benzamidomethyl)triethylammonium chloride (1) in aqueous medium to afford methyl 4-(benzamidomethoxy)benzoate (3) in high yield. The title compound was characterized by elemental analysis, FT-IR, ${ }^{1} \mathrm{H}-\mathrm{NMR}$ and ${ }^{13} \mathrm{C}-\mathrm{NMR}$ spectroscopy.
\end{abstract}

Keywords: methylparabene; benzamidomethylation

This paper aims to present a compound similar to methyl 4-methoxybenzoate in which methyl from the methoxy group is replaced with a benzamidomethyl group. Methyl 4-methoxybenzoate, also known as methyl anisate, has been frequently used as pharmaceutical intermediate and in many organic syntheses [1] and in food as flavoring agent [2,3]. In addition, it can be found as volatile component in many plants and mushrooms [4-8].

Although (benzamidomethyl)triethylammonium chloride (1) is an excellent reagent for benzamidomethylation of phenols [9], in our previous work [10] we demonstrated that the phenol group at 4-hydroxybenzoic acid cannot be benzamidomethylated with $\mathbf{1}$ in aqueous media. The carboxylic group as a weak nucleophile in aqueous media does not react [11], but it deactivates the phenol group in the molecule of 4-hydroxybenzoic acid. Since in methylparabene (2) the carboxylic group is protected, the hydroxy group can be easily benzamidomethylated with $\mathbf{1}$ in aqueous media to give methyl 4-[(benzoylamino)methoxy]benzoate (3) (Scheme 1). 
Scheme 1. Synthetic route to the title compound 3.

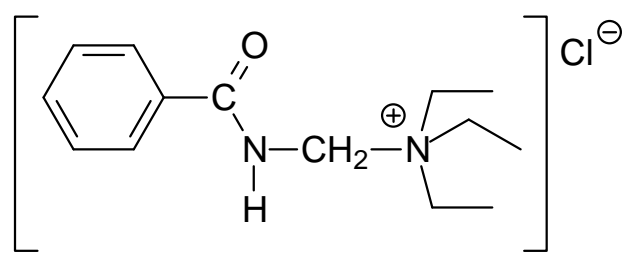

1<smiles>COC(=O)c1ccc(O)cc1</smiles>

2

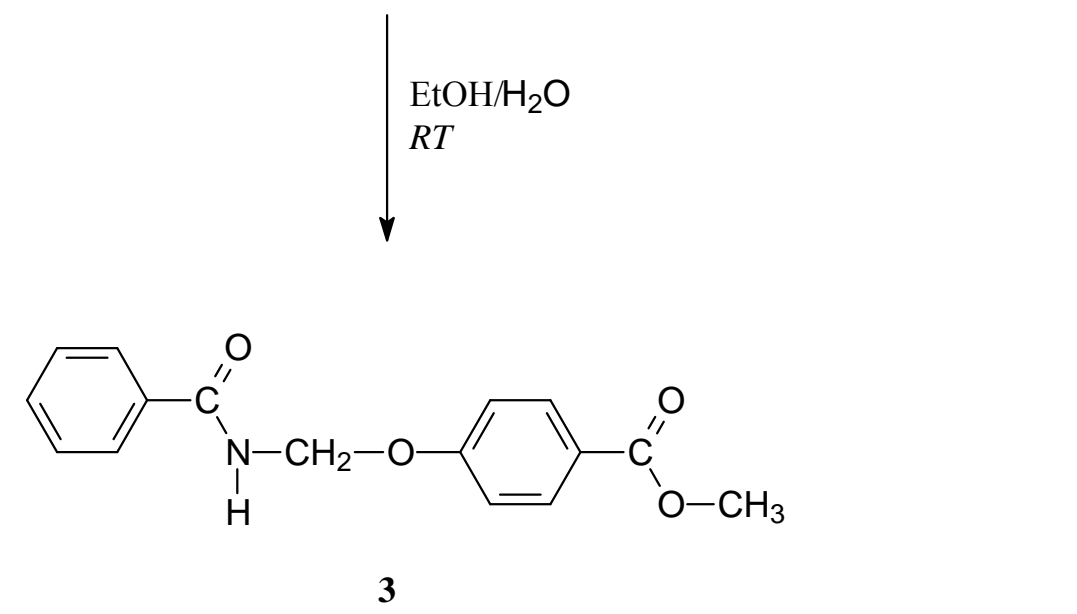

\section{Experimental}

Compound $\mathbf{1}$ is not commercially available and it was synthesised as described previously [9].

Methyl 4-[(benzoylamino)methoxy]benzoate (3)

To a mixture of powdered 1 (1.058 g, $3.9 \mathrm{mmol}), 2(0.501 \mathrm{~g}, 3.3 \mathrm{mmol})$, ethanol $(20 \mathrm{~mL})$ and triethylamine $(0.2 \mathrm{~mL})$, water was continually added, drop by drop, until a clear solution was obtained. The mixture was stirred for $5 \mathrm{~h}$ at room temperature. Then, water was added to the mixture until occurrence of a precipitate. The typical yield of crude colorless crystals with mp of $133-140{ }^{\circ} \mathrm{C}$ was $80 \%$. Purification was performed by dissolving the product in acetone followed by precipitation with water and subsequent recrystallization from toluene.

Melting point of pure crystals: $142-143{ }^{\circ} \mathrm{C}$ (uncorrected).

FT-IR (KBr): 3,290 (vNH), 1,718 (vOC=O), 1,663 (Amide I), 1,555 $\mathrm{cm}^{-1}$ (Amide II)

${ }^{1} \mathrm{H}-\mathrm{NMR}\left(250 \mathrm{MHz}, \mathrm{DMSO}-d_{6}\right)$ : $\delta / \mathrm{ppm} 9.64(\mathrm{t}, J=6.6 \mathrm{~Hz}, 1 \mathrm{H}, \mathrm{NH}) ; 7.93-7.15$ (9H, Ar); $5.41(\mathrm{~d}$, $\left.J=6.6 \mathrm{~Hz}, 2 \mathrm{H}, \mathrm{N}-\mathrm{CH}_{2}-\mathrm{O}\right) ; 3.81\left(\mathrm{~s}, 3 \mathrm{H}, \mathrm{CH}_{3}\right)$

${ }^{13} \mathrm{C}-\mathrm{NMR}\left(63 \mathrm{MHz}, \mathrm{DMSO}-d_{6}\right): \delta / \mathrm{ppm} 167.0(\mathrm{C}=\mathrm{O}) ; 165.9(\mathrm{C}=\mathrm{O}) ; 68.7\left(\mathrm{CH}_{2}\right) ; 51.9\left(\mathrm{CH}_{3}\right) ; \mathrm{Ar}: 160.8$, $133.3,132.1,131.2,128.6,127.5,122.3,115.2$.

Anal. Calcd. (found) for $\mathrm{C}_{16} \mathrm{H}_{15} \mathrm{NO}_{4}$ : C, 67.36 (67.55); H, 5.30 (5.41); N, 4.91 (5.07). 


\section{References}

1. Wang, H.; Pullambhatla, M.; Guilarte, T.R.; Mease, R.C.; Pomper, M.G.; Synthesis of [125I]iodoDPA-713: A new probe for imaging inflammation. Biochem. Biophys. Res Commun. 2009, 389, 80-83.

2. Perriot, R.; Breme, K.; Meierhenrich, U.J.; Carenini, E.; Ferrando, G.; Baldovini, N. Chemical composition of French mimosa absolute oil. J. Agric. Food Chem. 2010, 58, 1844-1849.

3. Panda, H. Perfumes and Flavours Technology Handbook; Asia Pacific Business Press Inc: Delhi, India, 2010.

4. Rapior, S.; Breheret, S.; Talou, T.; Pélissier, Y.; Bessière, J.-M. The anise-like odor of Clitocybe odora, Lentinellus cochleatus and Agaricus essettei. Mycologia 2002, 94, 373-376.

5. Binder, R.G.; Flath, R.A. Volatile components of pineapple guava. J. Agric. Food Chem. 1989, 37, 734-736.

6. Hardy, P.J.; Michael, B.J. Volatile components of feijoa fruits. Phytochemistry 1970, 9, 1355-1357.

7. Shaw, J.G.; Ellingham, P.J.; Birch, E.J. Volatile constituents of feijoa-headspace analysis of intact fruit. J. Sci. Food Agric. 1983, 34, 743-747.

8. Ceballos, L.; Pino, J.A.; Quijano-Celis C.E.; Dago A. Optimization of a HS-SPME/GC-MS Method for determination of volatile compounds in some Cuban unifloral honeys. J. Food Quality 2010, 33, 507-528.

9. Popovski, E.; Klisarova, L.; Vikic-Topic, D. Simple method for benzamidomethylation of phenols in water solution. Synth. Commun. 1999, 29, 3451-3458.

10. Popovski, E.; Mladenovska, K. (Benzoylamino)methyl 4-hydroxybenzoate. Molbank 2010, 2010, M658.

11. Popovski, E.; Klisarova, L.; Vikic-Topic, D. Benzamidomethylation with (benzamidomethyl)triethylammonium chloride 2. A simple method for benzamidomethylation of thiols, amines and carboxylic acids. Molecules 2000, 5, 927-936.

(C) 2010 by the authors; licensee MDPI, Basel, Switzerland. This article is an open access article distributed under the terms and conditions of the Creative Commons Attribution license (http://creativecommons.org/licenses/by/3.0/). 